\title{
ESCENARIO PARA UNA MAZURCA GALLEGA
}

\author{
Por \\ M. MANDIANES
}

A veces los novelistas muestran mejor y con más claridad la complejidad de la realidad que los sociólogos y los antropólogos quienes, con frecuenia, califican de ciencia su parafernalia lingüística y de ignorancia el arte de decir de manera sencilla las cosas complicadas. La novela tal vez sea el discurso con más posibilidades para mostrar la complejidad del hombre. Aunque los grandes escritores, observadores privilegiados, nos den una visión novelada de la realidad, el profesional de las ciencias sociales ha de saber espigar el dato objetivo para sistematizarlo y prescindir de la fabulación

El espacio hace posible el contacto y la reunión de varios elementos más o menos independientes que se convierten en un todo vertebrado. La relación del habitante con el lugar es muy diferente de la que puede establecer el nómada o el turista. El espacio está lleno de imágenes que dan una dimensión material a lo espiritual. La dimensión simbólica de las imágenes abren lo material a una dimensión espiritual. El hombre tiene necesidad de un espacio cargado de significado; a veces un lugar nos da lo que no podemos encontrar en todo el resto del mundo y, entonces, el resto del mundo puede no interesarnos para nada.

Aquí no entraré para nada en los aspectos puramente literarios de Mazurca para dos muertos de Camilo J. Cela; me interesan solamente sus puntos de referencia espaciales. Creo que es un error de los

"CUADERNOS DE ESTUDIOS GALLEGOS", Tomo XLIII, Fascículo 108, Santiago 1996. 
antropólogos, y muy concretamente de los gallegos, no tener más en cuenta el aporte de los novelistas y poetas al conocimiento de las estructuras que rigen la convivencia de sus paisanos. Sin ser moneda corriente, suele ocurrir con cierta frecuencia que muchos estudiosos «buscando embrollos para que su ciencia no caiga en desprecio, si es fácil, la hacen difícil y trabajosa con un disfraz de palabras, y se jactan de haber demostrado y probado científicamente... que el hombre es sustancia» ${ }^{1}$.

\section{1.- EL PAÍS Y SUS FRONTERAS}

«En España devoramos los nonumentos y las instituciones en aras del progreso, es una mala costumbre histórica de la que no escarmentamos, un vicio congénito con nuestra manera de ser del que no sabemos librarnos... Entre nosotros y en aras del progreso se tiraron puentes romanos, se convirtió en gravilla el noble pavimento de calzadas históricas, se derribaron murallas milenarias, se anegaron pueblos enteros con su iglesia románica a cambio de un pantano insuficiente, y se arrasaron torres militares aprovechando que ya no merodeaban por la mar abajo los corsarios sarracenos» ${ }^{2}$. En Galicia, la concentración parcelaria, tal como se está llevando a cabo, borra de sobre la faz de la tierra la configuración espacial que le es propia. En algún pueblo concentraron hasta el fondo de las escaleras de las casas; cuando llegaron los abuelos no reconocían el patio. «Lo han estropeado todo; son como perros rabiosos, muerden hasta en las piedras. En adelante nos dará lo mismo vivir aquí o en otro lugar que en el cementerio», me dijo un campesino después que su pueblo había sufrido la concentracíon parcelaria que se está haciendo al margen del espíritu de la ley ${ }^{3}$.

\footnotetext{
' F. Sánchez, Quod nihil scitur (Madrid, C. S. I. C., 1984), p. 79. Este autor influyó mucho, por ejemplo, en F. de Quevedo, cfr. Sueños (Ed. e int. de I. Arellano. Madrid, Cátedra, 1991), p. 271. 483

${ }_{2}$ Memorias, entendimientos y voluntades (en adelante MEV) (Barcelona, Plaza\&Janes, 1993), 81. 143; Cela, « $i$ Ah, las cabras!», Obras completas, 4 (Barcelona, Destino 1989), pp. 219-222

${ }^{3}$ O. Sotelo Blanco y M. Mandianes, A concentración parcelaria (Santiago, Sotelo Blanco, 1994); Ley de Concentración Parcelaria del 22 de agosto de 1985
}

"CUADERNOS DE ESTUdiOS GALLEGOS", Tomo XLIII, Fascículo 108, Santiago 1996. 
«El hombre ama la tierra que lo vio nacer, a veces no es bella pero es siempre suya, al sol y al viento y al agua de cada sitio no los puede mover ni siquiera el tiempo, tampoco se atreve, el hombre ama al sol y al viento y también al agua que lo vieron nacer, a veces son hostiles pero son siempre suyos, es saludable pegarse a la tierra y andar descalzo sobre la tierra porque la fuerza entra por los pies, el hombre se acaba convirtiendo en tierra y toda la vida nace de la tierra» ${ }^{4}$. «AA nosotros qué más nos da? El país es el país y la chaira es la chaira, mande quien mande» ${ }^{5}$. Para los gallegos patria es un sentimiento natural inspirado en realidades perceptibles por los cinco sentidos; es la tierra que les dió el ser y que los acogerá el día de la muerte. Ausentes de su suelo, viven en él espiritualmente, recuerdan el sonido de la campana del lugar, el árbol que crece frente a su casa, los peñascales contiguos. A donde quiera que vayan parece que llevan en sus ojos y en su corazón impresa la imagen de la patria gallega ${ }^{6}$.

«Airiños, airiños, aires, airiños da miña terra; airiños, airiños aires, airiños, levaime a ela» ${ }^{7}$.

Benicia, desde la frontera con León, se le escapó al marido y se vino otra vez para el país. "Yo soy de esta tierra y de aquí no me echará nadie; cuando me muera me convertiré en la tierra que da de comer a los tojos, me convertiré en la flor de oro del tojo». Los gallegos van a Portugal, más allá de los límites, a cambiar de aires, a estirar un poco las piernas a ver un curro de caballos y a contrabandear; pero cuando corren peligro piensan en volver al país. «Nada importa, lo que hay que estar es pegada a la tierra, es igual ser chino que de Ciudad Real pero hay que ser algo, eso de llevar zapatos de puta es lo de menos, hay que estar arraigado en algún

\footnotetext{
${ }^{4}$ Cristo versus Arizona (en adelante Arizona) (Barcelona, Seix Barral, 1988), 76. 3233. 36. 78.151

${ }^{5}$ Mazurca para dos muertos (en adelante Mazurca) (Barcelona, Seix Barral, 1984), 162; cfr. Pascual Duarte, 82. 164

${ }^{6}$ A. Rodríguez Castelao, Sempre en Galiza (Vigo, Galaxia, 1986), p. 43. 25. 230. 251; B. Vicetto, Historia de Galicia III (Ferrol, Taxonera, 1867), 135; M. Murguía, Galicia (Barcelona, 1888),p. XI

${ }^{7}$ R. de Castro, Poesías (Patronato Rosalia de Castro, 1982), p. 75
} 
sitio, lo demás no importa». «Adega es la memoria de la tierra hasta donde alcanza la vista, después ya viene el reino de León, el confín de Portugal, el extranjero y la tierra de moros». «Moncho Perguizas había dado la vuelta al mundo, siempre enrolado en barcos holandeses; lo que más le había gustado era Guayaquil». A pesar de ser el mundo tan grande, para algunos se vuelve una ratonera porque se le cierran todas las puertas. «Llueve sin misericordia alguna, a lo mejor llueve con mucha misericordia, sobre el mundo que queda de la borrada raya del monte para acá, lo que pasa más allá no se sabe y tampoco importa ${ }^{8}$.

Ya no queda nada más allá de la raya del monte que Nuestro Señor borró cuando mataron a Lázaro Codesal en tierra de moros; desde aquel día desgraciado ya nadie volvió a verla, a lo mejor se la llevaron más allá de las portillas de la Canda y el Padornelo. Entre Galicia y Portugal hay una franja de tierra que no es de nadie y sus habitantes ni son de un lado ni de otro, y hablan una lengua que ni es gallego ni portugués y los niños de este lado del río Limia van a la escuela al otro lado que es Portugal; el río Límia más que separar, une. La frontera no está muy guardada y el contrabando de ganado marcha bien. Lo prudente es no expresar los pensamientos en voz alta porque los forasteros sentimentales suelen llevar un habilidoso y vehemente verdugo escondido entre los pliegues del alma. De la gente de afuera no vale la pena preocuparse, a no ser para ponerse a salvo de su ruindad. Las voces extranjeras no llevan el entusiasmo a los corazones. «Los demás no salisteis de estos montes más que para hacer la guerra, yo ni eso», dice Robín. A los forasteros no hay ni por qué dejarlos hablar; cuando un hombre se aparta de la tierra en la que nació es porque algo le va mal en el organismo9. Fabián Minguela, llegado de más allá de los límites, estaba al mando de una pandilla de matones que sacaban de noche de sus casas a los hombres y los mataban y los debajan muertos en la cuneta; andaba siempre sacandole brillo a la navaja, nadie del pueblo salía nunca en defensa de él y no podía entrar en ninguna casa, lo mataron los perros a dentelladas y a las dos horas estalló una bomba de palenque. Las muertes de después de la guerra las causaron los que vinieron de fuera ${ }^{10}$.

\footnotetext{
${ }^{8}$ Mazurca, 13. 20. 22-23. 25. 38. 44. 47. 57. 162. 214; Arizona, 79. 202

${ }^{9}$ Mazurca, 123. 208. 218

${ }^{10}$ Mazurca, 23. 57. 64. 84. 135. 142
}

"CUADERNOS DE ESTUDIOS GALLEGOS", Tomo XLIII, Fascículo 108, Santiago 1996. 
Sergio sintió un gran bien en advertirse ligado sutilmente a los montes, al mar, a las rocas, al río, a las nubes oscuras. No hay fantasías en las almas de los pequeños campesinos. La severa madre tierra, buena y grave, sincera, educadora, no deja crecer las alas de ese pajaro de colorines que no sabe más que cantar. El ánima de Fiz Cotolevelo, cuando Fendetestas le propone marcharse a América, responde: «aquí nací y aquí viví y nada me interesa como esto. En otros sitios no conozco a nadie. No me voy». Algunos habitantes de la aldea se van a América o se hacen a la mar para hacer dinero o para que los vecinos se olviden de alguna falcatruada. Todos los que salen de la aldea se encuentran con un mundo desconocido, sin puntos de referencia que den significado a las cosas. Geraldo, como la mayoría de los aldeanos, se queda apegado para siempe a la tierra, en su casita del castro. Cuando están lejos y piensan en la Gándara se llenan sus ojos de llanto; sin embargo, el que no emigró no puede contar nada. Los pobres que nunca lograron ir a Cuba no son nada. Vuelven los emigrantes cuando sus casas están, ya casi, derruidas y se ponen a reconstruirlas ${ }^{11}$.

\section{EL ESPACIO URBANO}

El nido de la vida aldeana es la casa y el centro de cada casa es la lareira; en torno a ésta pasan sus miembros y los invitados, en animadas tertulias, horas sin termino en invierno. En la aldea todos saben el origen de cada uno y es difícil que alguien pueda engañar a cualquier otro. Todos los recovecos del territorio son significativos y cada uno tiene una historia particular. La ciudad es el lugar a donde se va a las putas, sus habitantes son seres anónimos y pintorescos, de donde llegan las ideas peligrosas.

1. La aldea

«En la casa de la abuela en la que vine al mundo, me siento feliz recorriendo de nuevo mis viejos paisajes familiares, Pedraza, Pazos, el

${ }^{11}$ W. Fernández Flórez, Volvoreta (Barcelona, Salvat, 1971), 41. 43. 72-73. 85. 159. 170. 174; idem, Bosque Animado (Madrid, Espasa-Calpe, 1983), 42. 25-26. 43

"CUADERNOS DE ESTUDIOS GALLEGOS", Tomo XLIII, Fascículo 108, Santiago 1996. 
río Sar, el monte Meda, los literarios pinares de Bastabales, la casa de La Retén con sus recuerdos de Rosalia, Herbón con sus pimientos y sus lampreas, hacía ya tiempo que no caminaba por este rincón para mi entrañable del que llegué a pensar que no volvería a verlo nunca». Dentro de casa no debe tocarse la gaita; cada cosa quiere su lugar. La casa de la señorita Ramona está fuera de la aldea y encierra misterio, muchas historias de pasiones, enfermedades y calamidades. En su jardín hay laureles y hortensias. Los niños malos se subían a los tejados y se paseaban por ellos. «Los que más envidian son los vecinos y los conocidos» ${ }^{12}$.

En la Mazurca para dos muertos se habla de los Gamuzo, de los Guxindes, de los Segade, Venceás, Moranes, Zurupetos y otras casas que, a veces, se desdoblan por los nuevos matrimonios. En la aldea «todos son mas o menos familia». Los Carroupos a los que pertenecía o Moucho, vinieron volando de Dios sabe donde. Las familias eran muy numerosas, de nueve, de cinco. La casa hay que defenderla hasta con la vida. Para tramar la muerte de Moucho se reunieron las casas de la aldea o de la parroquia; la reunión se disolvió poco a poco y en orden con el propósito de nadie decir nada. Las familias son como los ríos que no se cansan nunca de pasar; tienen borrachos, ciegos desgraciados, más o menos ropa. La casa es algo que tira mucho, pero la familia no siempre es positiva, a veces le quema a uno la sangre a fuego lento, lo crucifica. Hay muchas mujeres jovenes que se casan por aventura, por aburrimiento de vivir con sus padres. Hay sujetos que se avergüenzan de su familia y de su clase social $^{13}$.

Conflictos antiguos, aparentemente restañados, pueden dar lugar a pleitos actuales porque hay cosas que no pueden olvidarse; hasta los muertos se vengan y su venganza no recae necesariamente sobre la persona que los ha podido ofender en vida, puede recaer sobre cualquiera de la familia del ofensor ${ }^{14}$. «Todos iban yendo; los criados, las vacas, los de la Cruz del Souto, el camelio del jardín, los albaricoques de la huerta..., Chinto abarcó a todos los seres de la Gándara». Los criados de la casa de la señorita

\footnotetext{
${ }^{12}$ Esto dice cuando durante la guerra visita su casa del pueblo. $M E V, 214.305 ; M a-$ zurca, 9-10. 33. 48.62.65.87

${ }^{13}$ Mazurca, 11. 25. 33. 65-66. 75. 84. 104. 198. 212. 222-224. 242-243; La cruz, 63. 113. 134. 152

${ }^{14}$ Mazurca, 12. 34. 36-37. 147. 219. 231
}

"CUADERNOS DE ESTUDIOS GALLEGOS", Tomo XLIII, Fascículo 108, Santiago 1996. 
Ramona son como de casa. Los espacios están poblados de objetos familiares: cucharas de boj, zuecos, refajos que hacen ruido al moverse, jergones de hoja, animales domésticos, pájaros, toda clase de instrumentos de labranza, árboles, flores ${ }^{15}$.

Se sabe que familias son originarias de otra parte, especialmente si vienen de fuera del país. Siempre hay unos cuantos puestos de lado, como los Carroupos. Los habitantes de la aldea y de la parroquia se conocen todos, por eso nada ni nadie pasa desapercibido ni nada cae en saco roto. Algunas de las casas se unen con frecuencia para trabajar juntas y se reunen en las noches de invierno para hacer veladas. Durante las largas veladas de invierno, la gente charla, come, juega a las cartas y reza el rosario en torno al fuego del hogar y siempre hay alguien que cuenta cuentos, leyendas, historias; también pasan largos momentos en silencio. En los pueblos nunca faltan almas caritativas que se lo cuentan a uno todo; la privacidad es pequeña pero grande la solidaridad ${ }^{16}$.

El espacio son rincones significativos; «se veían en una cueva del pinar de Bouzas en la que instalaron un nido de hortensias secas y una lareira para asar chorizos y también para calentarse». Gorecho Tundas se metio en un ataúd que había llevado a una cueva y lo roció con petroleo y allí se prendió fuego y ardió como una tea; murió retorciéndose pero sin decir ni $\mathrm{mu}^{17}$. En la aldea se oye el ruido de los árboles, el bramido del mar, el crujir de las vigas en la casa y el del jergón de hojas de maiz; se oye llamar a las personas por su nombre, el paso lento de los bueyes, el tic-tac del corazón, el chapotear de las gentes en el lodo y los zuecos claveteados de Chinto, se oye maullar a los gatos, ladrar a los perros, el estampido de las escopetas de los cazadores y la gente va silbando por los caminos como la cosa más natural del mundo; hasta se oye el ruido que hacen las personas al sorber la comida. El ruido cohabita con el silencio; hay momentos en los que no se oye nada; las personas, los animales y la misma nauraleza están sumidos en un obstinado silencio. La gente, a veces, tiene el olor de los bueyes de su tierra, y el ambiente está cargado de aroma campesino. El viento trae el olor y la humedad de las olas del mar

\footnotetext{
${ }^{15}$ Volvoreta, XIX-XX; p. 113; Bosque Animado, 88-89. 159. 181-182

${ }^{16}$ Mazurca, 11. 14-15. 22-23. 25. 35. 86. 130; Pascual Duarte, cap. 2

${ }^{17}$ Mazurca, 12. 14. 78. 125. 211
}

"CUADERNOS DE ESTUDIOS GALLEGOS", Tomo XLIII, Fascículo 108, Santiago 1996. 
que parece un cielo debajo del otro cielo y mirándolo los campesinos se olvidan del tiempo. El túnel es como una sepultura sin fondo ${ }^{18}$.

«En el cementerio brota el manantial de agua clara que lava los huesos de los muertos, también el higado extrañamente frío de los muertos; le llaman la fuente de Miangueiro y en ella se mojan las carnes los leprosos, para encontrar alivio». En las fuentes de los cementerios no suele haber ranas pero a veces las hay sin que nadie sepa de donde pueden haber venido. Mosquitos hay muchos ${ }^{19}$. Choniña la Dulce pone cuernos a su marido con dos de sus empleados; como es discreta nadie lo sabe. A Santos Cófora Leitón, sesentón, su mujer, una joven bien parecida, en el campanario de la iglesia le pone los cuernos con el cura y él no los sabe llevar con dignidad y se va a Orense a que le peguen ladillas para vengarse del clérigo. Este cuando se entera, se rie y dice: «los campanarios están infectados de ladillas». Don Clemente no pudo aguantar más la cornamenta y se pegó un tiro con la escoteta sentado en la sala de su casa. Adolfiño Choqueiro aguantó mal los cuernos y se colgó del gancho de colgar la ropa en el armario ${ }^{20}$.

\section{La ciudad}

En contraste con el mundo rural, en donde todo el mundo se conoce y es una gran familia, la ciudad es una colmena en donde la vida discurre desordenadamente; el mundo en la ciudad puede reducirse a un café, lleno de gente. Los clientes de los cafés son gentes que creen que las cosas pasan porque sí, que no merece la pena poner remedio a nada; el corazón del café late como el de un enfermo; así toda la vida, día, noche, invierno y verano. En la ciudad, la vida trascurre en el café sin pensar en nada, meditando en nada, la gente vive como en un agujero; los bancos son como una antología de los sinsabores y de casi todas las desdichas; la gente pasa en ellos hora tras hora, hasta toda una vida, sin que nadie sepa nunca, demasiado a ciencia cierta, qué es lo que pasa. «Siguen jugando al tren $\sin$ fe, sin esperanza, incluso sin caridad, como cumpliendo un peno-

\footnotetext{
${ }^{18}$ Volvoreta, 27- 28. 50. 55. 120. 127. 129. 132. 146. 175; Bosque Animado, 36. 207 208 
so deber». Uno nunca sabe con quién tropieza. Martín Marco, símbolo de la bondad y la belleza, mira la vida como un niño acorralado y vaga sin querer irse a la cama ${ }^{21}$.

En la ciudad estos niveles practicamente desaparecen para dar paso a una sociedad que se organiza por clases; «la Coruña es una ciudad muy clasista y exclusiva, primero los coruñeses de la Ciudad Vieja, después los del Ensanche y después ya veremos. Eso es todo ${ }^{22}$. Las ideas peligrosas llegan al campo desde la ciudad. «Esta catástrofe viene de las ideas y malas mañas de la ciudad azotando el campo, mientras la gente no vuelva a meterse en sus casas todo andará revuelto» ${ }^{23}$. La ciudad huele a vómito y a sudor agrio de cuerpos sudados, el olor a romero de la aldea se cambia por el olor de un tarro de perfume. Los arrabales vomitan legiones de mozos incivilizados y la ciudad legiones de mujerzuelas en los bailes. Los aldeanos cuando van a la ciudad siguen hablando de sus cosas, y se transforman cuando vuelven al lugar de donde son. Para los aldeanos, los habitantes de la ciudad son seres anónimos y pintorescos; los de la aldea en la ciudad sienten necesidad de oir hablar de aquella. «No sé, le temo mucho al ascenso. Pudieran trasladarme, alejarme de aquí, quizá hacerme marchar otra vez a Castilla. Aquella Castilla horrible, seca, amarillenta!». «Una noche, en Madrid, oyendo cantar inesperadamente en el real a las masas Clavé, rompió en solo por una morriña gigantesca, y si al salir del teatro hubiese podido hacerlo, aquella misma noche hubiese tomado el tren para Galicia». Volvoreta y Hermelinda se van a la ciudad que es el refugio de toda muchachita campesina ante toda suerte de dificultades ${ }^{24}$.

La Marraca, la leñadora de la pradera de Francelos, tuvo doce hijas; ninguna llegó doncella a los diez años y todas se ganaron la vida con el coño. Las putas no guardan las formas ni la higiene y están llenas de ladillas; los hombres las atrapan en la casa de la Parrocha de Orense. Todos los lupanares, prostíbulos, gimnásticos y amorosos burdeles son de mansa y próvida saudade y alegría. Anunciación Sabadelle se largó de su casa pero no llegó muy lejos; se quedó en Orense procedente de Lalín

\footnotetext{
${ }^{21}$ Camilo. J. Cela, Colmena (Madrid, Castalia, 1990), 115. 119. 123. 132. 139. 151152. 156. 180. 318. 319; Cfr. Criticón, $3^{\mathrm{a}}$, 8: «La cueva de la nada»

${ }^{22}$ Camilo J. Cela, La cruz de San Andrés (Barcelona, Planeta, 1994), 11

${ }^{23}$ Mazurca, 170
}

"CUADERNOS DE ESTUDIOS GALLEGOS", Tomo XLIII, Fascículo 108, Santiago 1996. 
y nunca más se atrevió a volver a su casa por si su padre le partía la cara. Las putas tontas no salen jamás de pobres. Algunas son muy rezadøras y hay burdeles tachonados de estampas; a algunos clientes les da un poco de aprensión el tener que hacerlo entre la Virgen del Perpetuo Socorro, el Sagrado Corazón y Santa Rita. Es cierto, la prostituta vive de espaldas a la ley de Dios, pero Pura, por ejemplo «en el fondo es buena persona». María la Portuguesa protegió a Lóla cuando llegó descalza de El Barco a Orense sin siquiera saber hablar castellano. El P. Santisteban tronaba en sus sermones contra los lupanares, las ramerías, lugares de lenocinio y de desahogo ${ }^{25}$.

Raimundo el de los Casandulfes se inició en casas de prostitución de Santiago siendo estudiante en la univesidad. «Lacrau va de putas una vez al mes y no mira para el dinero, el se gasta lo que sea preciso, para esto trabaja». Algunas se hacen putas porque tienen que comer y todas han de tener mucho instinto si no quieren morirse de hambre; no todas ni siempre guardan la compostura ni son respetuosas con los clientes, les escupen en la cara, en la bragueta o en el vaso, les enseñan el culo y sacan las tetas por el escote. El que paga manda y las putas siguen las mismas reglas que las otras mercancías. El pueblo que no tiene prostíbulo ni cementerio no se puede llamar pueblo. Era fácil que al atravesar los límites de la parroquia o de la misma aldea, se formaran peleas y triscas; las había en las romerías y en la casa de la Parrocha en Orense si ésta no echaba a tiempo fuera a los liantes ${ }^{26}$.

\section{3.- EL ESPACIO SALVAJE}

En el espacio salvaje, están los santuarios a donde acuden los peregrinos en fechas fijas del año. San Andrés de Teixido han de acudir todos los gallegos de vivos o después de muertos. Al lado de cada santuario existe una fuente que resume en sí misma todo el simbolismo del agua. El mon-

\footnotetext{
${ }^{24}$ Bosque Animado, 31-32. 41; Volvoreta, 38. 40

${ }^{25}$ Mazurca, 28. 37. 69. 99. 160. 139. 157. 163. 184. 195-196. 203. 244

${ }^{26}$ Mazurca, 37. 60. 66. 91. 128. 142. 157. 211. 227; Cela, Izas, rabizas y colipoterras. Drama con acompañamiento de cachondeo y dolor de corazón, en Obras completas, 25 (Barcelona, Destino, 1990), p. 103; Arizona, 14. 21. 44-45. 54. 72. 115. 120. 130. 235. 237
} 
te, lugar salvaje sin santuario, está habitado por el lobo, simbólico de violencia, la guardia civil y los hombres que, después de la guerra, mataban al otro hombre sin pensarselo dos veces.

\section{San Andrés de Teixido}

Cuenta una tradición que cuando Nuestro Señor andaba por el mundo en compañía de San Pedro se le apareció San Andrés quien le expuso sus quejas por estar tan solo por aquellos parajes abruptos y solitarios, y de que tanta gente acudiera a visitar a Santiago; entonces el Señor prometió a San Andrés que su romería habría de ser de las más sonadas del mundo. El santuario de San Andrés de Teixido tal vez sea una de tantas reminiscencias de la mitología, profundamente naturalista. Galicia ha sustituido los credos sin alterar los cultos y así puede sospecharse que estos lugares donde la tradición viste sus galas más originales traen su origen remoto, precristiano con el que se enlazan en el caso concreto que nos mueve $^{27}$.

Los devotos, muchas veces, antes de emprender la peregrinación a San Andrés, van al cementerio e invitan a tal o cual muerto para que los acompañe a la romería y lo tratan como si estuviera vivo. Pueden hablar con el difunto y si se detienen en el camino han de avisarlo porque el difunto no ve pero oye. A la hora de comer se invita a un mendigo que se siente a la mesa en la plaza del difunto. Los romeros líbranse muy mucho de ni siquiera molestar a los reptiles que hallan al paso, porque pueden. ser almas en pena de aquellos infelices descuidados, indiferentes o descreidos que no habiendo hecho en vida la obligada romería, están obligados después de su muerte a hacerla. «Nuestro Señor Jesucristo dispuso que todos los cristianos que quisieran salvar el alma tendrían que haber viajado por lo menos una vez al santuario, en vida o en muerte, y entonces convertidos en animales irracionales, por eso se dice que a San Andrés de Teixido vai de morto o que non foi de vivo. Por el confín de San Andrés de Teixido, en el cabo del mundo, frente a la mar que nadie navega porque las olas son como montes, se ven tropeles de escorpiones, lagartos,

${ }^{27}$ F. Maciñeira, San Andrés de Teixido. Historia, leyendas y tradiciones (Roel, Coruña s/f); L. Carré, Las leyendas tradicionales gallegas (Madrid, Espasa-Calpe, 1977), p. $78-80$

"CUADERNOS DE ESTUDIOS GALLEGOS", Tomo XLIII, Fascículo 108, Santiago 1996. 
sapos y otras alimañas mansas y bravas, hasta viboras y tarántulas peludas, que llevan dentro el ánima de quienes no fueron romeros a su tiempo, así podrán salvarse los avisados por Dios Nuestro Señor». Subsiste aún la curiosa costumbre tradicinal de que todo romero que, por primera vez, va a San Andrés de Teixido en cumplimiento de algún voto, arroja una pesada piedra, recogida por el monte, en cualquiera de los grandes montones, llamados amilladoiros, que con la acumulación de las mismas se han ido formando en el transcurso de los siglos, a los lados de los ásperos cami$\operatorname{nos}^{28}$.

Tanis Gamuzo era un liante de cuidado; tenía pintadas sus iniciales en su palo de peleas que era muy duro. «Está en la carcel porque mató a uno de un palo, mire usted que se reparten palos en las romerías, bueno, pues uno, se conoce que el que va envenenado, produce la desgracia». A los Guxindes siempre les gustó andar a palos en las romerías pero ahora estan medio idos. Los matones que matan a gente del pueblo son de afuera. La sangre de fuera del país no es de fiar. Los Carroupos son extranjeros y tienen una sangre diferente a la de los demás y por eso matan a los del pueblo. Micifú, uno de los hombres sangrientos, que mataba a la gente después del paseillo, era de Zamora, de más allá de los límites; fue uno de los primeros jefes de la Escuadra del Amanecer ${ }^{29}$.

En Galicia existen muchos santuarios y casi todos están en la cima de algúna montaña. A los pies de la visitadísima ermita de San Andrés de Teixido brota de entre las peñas un manantial, llamado Fonte do Santo, a la que todos los devotos van a beber por cosntituir una costumbre de la romería. Si el pedazo de pan que echan a la fuente flota, el santo les será propicio y habrá atendido sus peticiones. Ya los antiguos habitantes d Galicia echaban pan al agua ${ }^{30}$.

La ciudad de Antioquia duerme sepultada bajo las aguas de Antela. Las ranas de la laguna de Antela son primas de algunas personas; sus aguas son las mas antiguas de cuantas se conocen. De la rana Liorta de la laguna de Antela proceden nueve familias distintas, entre ellas los Cela.

\footnotetext{
${ }^{28}$ Mazurca, 21. 136; L. Carré, Las leyendas..., op. cit., p. 125-129

${ }^{29}$ Mazurca, 40.46. 612. 64. 67. 80-84. 88. 97. 123. 143-145. 150-151. 208. 212. 219.

${ }^{30}$ Mazurca, 32. 85. 221; Bosque Animado, 11-12. 30. 41-42
} 231

"CUADERNOS DE ESTUDIOS GALLEGOS", Tomo XLIII, Fascículo 108, Santiago 1996. 
Las ranas del condado de Tipperary, en Irlanda, son tan nobles como ls de la laguna de Antela. Un gallo canta, cada año, la noche de San Juan desde la torre de la iglesia de la ciudad anegada bajo las aguas de la Laguna de Antela para recordar a los habitantes sus pecados. Hay un lobo ahorcado en el badajo de la campana más grande sumergida en las aguas de la laguna de Antela. El perdón a los pecadores de Antioquía ni les llega ni les llegará nunca porque están condenados por toda la eternidad. Llegando al fondo de sus aguas, se pierde la memoria ${ }^{31}$.

Hay otras célebres ciudades gallegas sepultadas bajo las aguas de alguna laguna porque un día pasó por allí Nuestro Señor pidiendo posada y una taza de caldo; los habitantes en vez de acogerlo lo insultó llamandole vagabundo. Al poco tiempo, los habitantes oyeron un gran estruendo y el borbollar de las aguas como si el mar se volcara sobre la tierra. Los gritos de pavor estremecían. Atemorizados vieron que la ciudad de Doniños se sumergía inundada por un colosal torrente que, sin saber cómo, allí mismo había surgido entre los peñascos que la cercaban. Las aguas de la laguna de Lamas, por motivos parecidos, sumergieron la ciudad de Beria ${ }^{32}$.

Catuxa, la parva, se bañaba en la represa del molino con hombres que la enguilaban a flote y a la sombra de los helechos. Las mujeres, con harta frecuencia, ignoran el dolor que causan con sus huidas a la descubierta o largas cambiadas, pese a lo mucho que suele compensar la paz que dejan $^{33}$. En Galicia es importante desde el punto de vista simbólico el Limia

${ }^{31}$ Mazurca, 39-40. 45-46. 66-67. 80. 85. 98-99. 105. 119. 143; cfr. J. Taboada, «La leyenda de la laguna de Antela», en Cuadernos de Estudios Gallegos XXIV(1969), 348362

${ }^{32}$ L. Carré, Las leyendas..., op. cit., pp. 51-53. 90-92. En el Condado de Dongall había un célebre lago, Earne o Erne, formado por el río Liffer. En este lago hay algunas isletas y, entre ellas, una a la que los irlandeses llaman Isla del Purgatorio, por estar en ella la famosa cueva a la que se dio el nombre de Purgatorio de San Patricio. En la otra versión, el purgatorio está en el fondo de un pozo lo que podría interpretarse, también, como una ciudad sumergida. Cfr. B. Feijoó, Teatro crítico universal III (Madrid, EspaCalpe, 1975), p. 110. Tal vez la historia de las ciudades sumergidas no sea más que un intento de cristianizar el viaje de Eneas a los infiernos. El Purgatorio de San Patricio de Perellós se puede considerar como una ciudad de las sumergidas; para llegar allí hay que utilizar barca; también hay un río que el peregrino debe atravesar para ir a la otra orilla. Cfr. Odisea (Barcelona, Orbis, 1982), p. 157; Eneida (Madrid, Alianza, 1991), libro VI; Perellós, Viatge al Purgatori de Sant Patrici (Barcelona, 1917), p. 32

${ }^{33}$ Mazurca, 18. 20. 34. 45. 49. 60. 83. 94. 123. 126. 225

"CUADERNOS DE ESTUDIOS GALLEGOS", Tomo XLIII, Fascículo 108, Santiago 1996. 
al que los autores clásicos hacen varias alusiones; es el río del olvido. El autor de Mazurca transfiere a la laguna de Antela las propiedades que la mitología atribuye al río Limia. Creían los antiguos habitantes de Galicia que quien lo atravesaba perdía la memoria. Dicen que cuando Bruto llegó a la orilla del río del Olvido tuvo que ser el primero en atravesarlo y desde la otra orilla llamar a los soldados uno por uno por sus nombres porque no querían pasar por miedo a perder la memoria. La causa de esta leyenda es, según Strabón, el hecho de que los Turdulos que procedían de Andalucia quedaran dispersos al otro lado del Limia despues de perder a su jefe sin regresar a su patria. Autores hay que identifican el río Letes de los griegos con el río Limia o que, al menos, le asignan la misma función mítica ${ }^{34}$.

\section{El monte}

Los hombres de Fabián Minguela llenaban las cunetas de hombres muertos; al padre de Rosicler lo pasearon en Orense durante la guerra civil. El campo gallego antes era el bazar del cielo y la zurra bárbara y dolorosa de la guerra lo convirtió en el asilo del limbo. Con la guerra, Galicia hasta ha perdido los papeles del meigallo. Por muchas partes levantaron partida los guerrilleros; en Galicia hubo unas cuantas bandas famosas. La afición a la muerte hace prosperar las fábricas de ataúdes que pronto acabarán con los bosques de pinos ${ }^{35}$.

El monte es el lugar de la guarcia civil y el apropiado para que los hombres armados anden a tiros; en cada rincón del monte hay una mancha de sangre, a veces vale para dar de comer a una flor; sólo los extranjeros se saltan la ley del monte. Las cosas del monte son cosas de familia y han de arreglarse en familia con mucha paciencia y sin hablar con nadie de ellas. Los que matan a alguien para que su crimen sea olvidado de todos se apartan unos cuantos años al monte; quien anda haciendo el mal,

${ }^{34}$ Salustio, Hist. 3, 44; Strabón, III, 3, 4-5; Silio, I, I, 235; Plinio, Hist. Nát., IV, 112; Plutarco, Quaest. Roma., 34; Floro, I, 33, 12; Apiano, 73-74; Tito Livio, Per., 55; Mela, III, 10; Ttin. Prov. Ant. Aug., 429, 6; Toloméo, II, 6, 1; Odisea, 152. 143. 146-148; Eneida, 168-170; I; Millán, «Los nombres del río Limia...», en Actas do II coloquio galaico-minhoto,_II (Santiago de Compostela 1984), 343-385

${ }^{35}$ Mazurca, 16. 104. 43. 86. 127. 131. 154. 161. 165. 167. 169. 172-173. 193. 201. 204. 207-209. 219. 220; Cela, «El séptimo mandamiento. La razón social Candelas, Balseiro y Paco el sastre», Obras completas, op. cit., vol. 2. pp. 326-329

"CUADERNOS DE ESTUDIOS GALLEGOS", Tomo XLIII, Fascículo 108, Santiago 1996. 
más tarde o más temprano, lo cazan. Algunos hombres, durante la guerra y después, tuvieron que vivir mucho tiempo en el monte y cuando bajaban a los forasteros ni los saludaban ${ }^{36}$.

Los perros de Tanis mataron a dentelladas a Moucho Carroupo, un forastero, al lado de una fuente a la que se había acercado a beber y a la criada muda de los Venceás. Cuando aquel va a cumplir con la ley del monte lleva sólo dos perros; si se llevan más de tres y les da la vena, pierden el respeto al amo, se conoce que el hacer carne les nubla la vista y los vuelve locos. El perro hoza la mandrágora en cuya raiz se figuran las partes del hombre. Los perros de Galicia son simpáticos, listos y furabolos -el can de gando, el can de montaña, el can de palleiro, el can de presa-, pero no suelen ser de tan buena casta como los leoneses. Los perros aúllan de aburrimiento, cuando hay luna llena o para anunciar la muerte de alguien ${ }^{37}$. Los perros salen de los patios ladrando detrás de los caminantes y los acompañan largo trecho, desde la colina se oye ladrar los perros de aldeas lejanas, la gente habla con ellos y duermen al lado de las chimeneas. El hombre cuando quiere dormir, da a sus propiedades por rodrigón al perro, único animal capaz de comprender y de identificarse con nuestras propias preocupaciones; posée la noción exacta de la propiedad. Ningún can de nuestras aldeas se lanzará sobre las pantorrillas de quien camine por el sendero público de la huerta que él guarda ${ }^{38}$.

Cuando San Roldán anduvo por el Barco de Valdeorras, por Rúa de Petín y por Rubiana matando sarracenos, se encontró con dos hermosísimas moras subiendo a la sierra de Enciña de Lastre a las que no pudo dar alcance a pesar de que las persiguió con el caballo a galope, tan a galope que lo reventó; «desesperado ante la huida de las bellas, San Roldán les echó la maldición y las dos se convirtieron en los Seixos Brancos, en las dos piedras de blanquisimo cuarzo que aún guardan el camino, una a cada

${ }^{36}$ Mazurca, 19. 24-25. 29. 47. 84. 88. 94. 128. 130. 144. 149. 174-175. 187. 190. 219. 210. 231. 247; Colmena, 55. 152. 108-109. 213; Génesis, 34, 25-31 Exodo, 21, 12 $14 ; 24,10-13$

${ }^{37}$ Mazurca, 26-27. 56. 61. 82. 111. 114. 122. 131. 172. 190. 200. 236. 241. 246-248

${ }^{38}$ Mazurca, 111. 190; Pascual Duarte, cap. 1; Bosque Animado, 60. 64-65; Volvoreta, 82. 97; R. de Valle-Inclán, Sonata de Otoño (Madrid, Espasa-Calpe, 1985), 73. 79; Cela, «Pequeña parabola de Chindo, perro de ciego» y «El perro del Mina Cantiquín», en Obras completas, op. cit., vol. 2, p. 503-510

"CUADERNOS DE ESTUDIOS GALLEGOS", Tomo XLIII, Fascículo 108, Santiago 1996. 
lado». San Roldán se le apareció a Benicia y, al parecer, le habló en latín. San Roldán, un fantasma, hablaba latín y el ánima de Benitoña que mató el hombre lobo flotaba por la carballeira mucho tiempo después ${ }^{39}$.

En Galicia aún viven muchos moros, lo que pasa es que no se ven porque están muertos. Los moros son de hace mucho tiempo. Basilio Ribadelo de Sobrado del Obispo carretaba de noche vino de los moros, para que no lo viesen los cristianos, en pago recibía unas lajas de pizarra que por el camino se le iban convirtiendo en oro a condición de que no dijera nada a nadie bajo ningún pretexto; un día su mujer a quien había hecho partícipe del secreto, se fue de la lengua y lo perdió todo. «Los encantos son valerosos pero obedientes y no dejan nunca de cumplir los mandamientos de Dios, los encantos guardan los tres tesoros, los de los moros, los de los godos y los de los frailes pero los entregan con toda mansedumbre cuando se lee el Ciprianillo. Si el encanto deja de ser un dragón o un culebrón y se convierte en fantasma, entonces se hace encantamiento y puede escapar silbando por el aire». Los niños sin bautizar son como moros y su unto se puede utilizar para ungüentos ${ }^{40}$.

«En el monte hay una peña a la que llaman o Peiteador da Raína que tiene forma de confesionario, con su asiento y su ventanillo, y en ella suele sentarse la reina mora mientras le peinan la trenza y le asoellan los tesoros; los cristianos podían ver la escena desde lejos pero, si se acercaban, desaparecía todo como por ensalmo... Una mañana Mariquiña vio una mora viejísima y de muy noble aspecto que le llamaba por su nombre... La vieja era la misma reina mora del monte das Cantariñas» que pidió a Mariquiña una cuenca de leche. «La vieja le llenó el pañuelo sin explicar de qué y le ordenó que no dijese nada a nadie y que tampoco lo mirase hasta llegar a casa y estar sentadita a la lareira y con la puerta y las ventanas cerradas... Mariquiña cumplió cuanto le mandara y cuando desató el pañuelo lo vio todo lleno de monedas de oro. La madre de Mariquiña se sintió muy feliz y por más que preguntó, no supo de donde saliera

${ }^{39}$ Mazurca, 94; cfr. F. Bouza Brey, «Fortuna de las canciones de gesta y del heroe Roldan en el románico compostelano y en la tradición gallega, en Etnografía, I Vigo, Xerais, 1982», p. 27-60

${ }^{40}$ Mazurca, 28. 44-47. 77-79. 80. 104. 107-108. 115. 126. 143. 147. 179. 183.188. 215; Volvoreta, 78

"CUADERNOS DE ESTUdIOS GALLEGOS", Tomo XLIII, Fascículo 108, Santiago 1996. 
aquel caudal... Al día siguiente Mariquiña volvió al monte y se repitió la escena». Un día, Mariquiña se fue de la lengua y lo contó todo; entonces, el oro se volvió grava del camino y nada más se supo ni de su cuerpo ni de su alma. Un día las gentes del pueblo salieron a buscarla y se oyó esta voz: «A Mariquiña por lengoreteira está na miña barriguiña fritida con allo e manteiga». La cristianización de la mitología indoeuropea condenó al infierno y a los lugares sucios y abandonados bajo el nombre de mouras y encantos a muchas bellas señoritas que habitaban en los palacios subterráneos o en medio del mar ${ }^{41}$. Los hombres no pueden quedarse dormidos en el monte porque vendrá una serpiente y se les meterá por la boca. El lagarto de la reina Loba sabía la tabla de multiplicar y las capitales de Europa, despiertan con el rabo a los hombres que, dormidos en el monte, corren el peligro de que una serpiente se les meta por la boca, pero se echan al color rojo que es el de la sangre menstrual y simboliza la mujer. En muchas ocasiones, la serpiente aparece como la guardiana de los tesoros y de las mujeres encantadas ${ }^{42}$.

Abundan en Galicia y en Portugal los caballos del monte que son recogidos en los curros para marcarlos y cortarles las crines; se trata de auténticas pruebas para pasar de rapaz a mozo y de mozo a hombre. Hacerlo según dictan los cánones es todo un arte: hay hombres muy diestros en ello que ganan todas las apuestas. Los marcan a hierro y fuego y los rapan; «la rapa se hace como se puede, allí no se esmera nadie, y el caso es acabar rápido y cuanto antes». Todos los caballos del monte son bigotudos, tienen mucho genio y voluntad, y muerden ${ }^{43}$. Los gallegos creen

${ }^{41}$ Mazurca, 107. 147-148; cfr. M. del M. Llinares, Mouros, ánimas demonios (Madrid, Akal, 1990); V. Risco, «Los tesoros legendarios en Galicia», RDTP, VI (1950), $185-213$ y $403-429$

${ }^{42}$ Mazurca, 12. 13. 21. 39. 95. 143. 172; R. de Valle-Inclán, Romance de Lobos (Madrid, Espasa-Calpe, 1984), p. 113; Bosque animado, 97-98; Carré, 246-247; V. Risco, «El lobishome», en RDTP I (1944-45), 514-553; cfr. M. Mandianes, «La serpiente y el cerdo en Galicia», Anthropológica, 13-14 (1993), pp. 219-233; Fina M. Antón y M. Mandianes, «Bouza Brey e a ofiolatría en Galicia», en Actas do simposio de antropoloxía. In memorian Fermín Bouza Brey (Santiago, 1994), pp. 67-75 y «Le serpent maître du temps en Galice», en Le temps mythique de l'Europe, II (Strasbourg, Conseill de l'Europe, 1994), pp. 116-123

${ }^{43}$ Mazurca, 13.40-42; cfr. M Cabada, A rapa das bestas de Sabucedo. Historia e antropoloxía dunha tradición (Vigo, Ir Indo, 1992)

"CUADERNOS DE ESTUDIOS GALLEGOS", Tomo XLIII, Fascículo 108, Santiago 1996. 
que el caballo es mensajero del otro mundo porque cuando un caballo tropieza en una piedra del camino es señal de que una ánima necesitada nos pide que rezemos por su eterno descanso. Los galos ponían el caballo en relación con la barca que transporta a los muertos al otro mundo y grababan su imagen sobre muchos túmulos funerarios y en muchos casos se puede ver como es un animal de muertos. Los griegos también creían algo parecido: el hombre que lleva a los muertos viene en un carro de caballos. El caballo también es el medio que, a veces, utilizan los encantos para aparecerse a las señoritas ${ }^{44}$.

\section{CONCLUSIÓN}

Además de ser un placer, leer Mazurca para dos muertos es un paseo por las estructuras antropológicas de los gallegos porque actualiza la concepción del espacio tradicional que sirve de escenario a sus personajes. Por otra parte, cuando el lector conoce la mitología gallega, se da cuenta de que el novelista la conoce a fondo y la recrea en su obra jugando literariamente con ella; es decir, los elementos están sacados de la experiencia pero combinados según la imaginación del autor.

${ }^{44}$ En la Lusitania, cerca de la fortaleza Olisipón y del río Tajo las yeguas, vueltas hacia el favonio que sopla, reciben el espíritu del aire y paren el potro más veloz que no pasará de tres años de vida. Los autores clásicos son testigos de la velocidad, de la bravura y de la multitud de los caballos gallegos Justino, XLIV, 3, 1-9; Plinio, Hist. Nat., VIII, 166; Grattio, 513; Silio Itálico, XVI, 333-335; Carré, 37-39. 291-293; Eurípides, Tragedias I (Madrid, C. S. I. C., 1982), p. 38.

"CUADERNOS DE ESTUDIOS GALLEGOS", Tomo XLIII, Fascículo 108, Santiago 1996. 